\title{
EVOLVING VIRTUE
}

\author{
Alessandro D'Atri', Amihai Motro ${ }^{2}$ \\ ${ }^{I}$ CeRSI, LUISS “Guido Carli” University, Roma, ITALY, datri@luiss.it \\ ${ }^{2}$ CS Department, George Mason University, Fairfax, VA, USA, ami@gmu.edu
}

\begin{abstract}
One of the most attractive aspects of virtual enterprises is their agility: the inherent ability to adapt and evolve in response to changing market conditions. Evolving VirtuE is a formal framework within which such agility can be realized. Through the concepts of enterprise time, activity logging, and log mining, the recent behavior and performance of an enterprise may be studied, and corresponding evolutionary steps can be induced. These steps may be intended to benefit the operation of individual enterprise members, as well the enterprise as a whole. In addition, we examine enterprise creation, a period of rapid evolution that concludes when the enterprise reaches stability and begins transacting its business activities.
\end{abstract}

\section{INTRODUCTION}

One of the most attractive aspects of virtual enterprises is their agility: the inherent ability to adapt and evolve in response to changing market conditions [6]. This paper presents Evolving VirtuE, a model with capabilities for capturing the dynamic aspects of virtual enterprises. Evolving VirtuE incorporates the notions of time and activity logging. These features enable elaborate measurement of performance, thus providing the rationale for any future evolution of the virtual enterprise. Second, it examines in detail virtual enterprise creation, a period of rapid evolution that ends when the enterprise achieves stability. Finally, and perhaps most importantly, it provides a framework for studying the performance and behavior of virtual enterprises, and for evolving them accordingly.

In itself, Evolving VirtuE is an evolution of the VirtuE model [3, 4], a model that formalizes the basic principles and operations of virtual enterprises, concentrating on virtual enterprises that deal with information products (e-products). The purpose of VirtuE was threefold. Others had previously articulated the concept of virtual enterprises; yet, at the time, the literature did not show unanimity with respect to essential principles, precise terminology, or formal definitions. VirtuE was therefore an attempt to establish a uniform platform for virtual enterprises, in which existing concepts could be formalized and standardized. Second, such formal treatment enables deeper (often quantitative) investigation of additional aspects of virtual enterprises, thus advancing the area even further. Finally, a formal model is an

D'Atri, A., Motro, A., 2007, in IFIP International Federation for Information Processing, Volume 243, Establishing the Foundation of Collaborative Networks; eds. Camarinha-Matos, L., Afsarmanesh, H., Novais, P., Analide, C.; (Boston: Springer), pp. 317-325. 
essential step before undertaking an implementation of a software system that supports the activities of virtual enterprises.

Yet, the VirtuE model could be described as "static": It provides means for capturing the operations of stable virtual enterprises, but it lacks capabilities for modeling the dynamic aspects of virtual enterprises. The model described here seeks to extend the capabilities of VirtuE with various features related to enterprise dynamics.

Evolving VirtuE is described in two sections: In Section 3 we introduce the new features of the model, and in Section 4 we examine virtual enterprise creation, and we outline the framework for learning and evolution. We conclude with a short review of related work in Section 5, and a brief summary in Section 6. We begin with a review of the primary concepts of VirtuE.

\section{VIRTUE}

Essentially, the VirtuE model defines a distributed environment for virtual enterprises. The model has three principal components. First, it defines a distributed infrastructure with concepts such as members, products, inventories, and production plans. Second, it defines transactions among members, to enable collaborative production of complex products. Finally, it provides means for the instrumentation of enterprises, to measure their performance and to govern their behavior. We retain without modification most of the concepts introduced in earlier papers, and we review here the primary concepts.

\subsection{Members}

A virtual enterprise-breeding environment (VBE) [1] is a community of business entities that are potential participants in business coalitions. Each virtual enterprise chooses its members from the VBE. The members are independent but have shared interests. They are independent in the sense that they remain autonomous and maintain their own assets. These assets include human, equipment or financial resources, as well as business expertise, such as knowledge about their production and delivery processes. Their shared interests are reflected in that they agree to cooperate with each other to produce joint products that are provided to common clients. After the community had been established, it could evolve because a new member joins or an exiting member departs. This form of evolution provides the virtual enterprise with flexibility and allows it to adapt to new market situations.

\subsection{Products}

In practice, virtual enterprises may produce many different kinds of products. In VirtuE, we consider only information products, of the type that can be delivered over computer networks. Information products are provided by members of the enterprise to their clients. This provision is the ultimate purpose of an enterprise. Information products are also exchanged among the members of the enterprise in the production phase that precedes the provision of a product to a client. We distinguish between two kinds of information products: content and process. Content is an information item; for example, a specific data table, a specific document, or a specific image. Process is 
an operation that modifies given content to provide new content; for example, summarization of a data table, encryption of a document, or compression of an image.

\subsection{Product dictionary}

All products, content as well as processes, are classified into product types. A product type describes the common attributes of all products of that type. For example, all images could be instances of the content type Image, and all compression processes could be instances of the process type Compression. We assume that all intensional information (i.e., types and their attributes) is maintained in an enterprise-wide resource called the dictionary. This global knowledge resource is available to every member of the enterprise. Every product in the virtual enterprise is an instance of a type described in the dictionary. The purpose of the dictionary is to assure semantic consistency across the enterprise.

\subsection{Local inventories and global catalog}

The products either used or created by each enterprise member are described in a local resource called inventory. Items in the inventory are instances of product types described in the dictionary. Among other information, the inventory specifies the source and target of each product. The source is either native or import: A native product is produced locally, whereas an import product is procured from another member of the enterprise. The target is either internal or export: An internal product is an intermediate product used by this member in the manufacturing of other products, whereas an export product may be delivered to other enterprise members. The product catalog is an enterprise-wide resource that lists the products that are available for procurement from enterprise members; i.e., it is the union of the products marked "export" in all inventories. Each member publishes his list of export products in this catalog and is responsible for keeping it updated. ' Note that products in the catalog are instances of the types in the dictionary. Hence, the dictionary regulates the catalog.

\subsection{Production plans}

Another designation of inventory products is whether they are basic or complex. A product is complex if it is derived from other products; otherwise, it is basic. For native complex product, production plans must be provided. A production plan specifies how other contents and processes are combined to derive the new product. In particular, it specifies the dependence of a product on products that must be procured from other members. Production plans are provided for both complex contents and complex processes, and a product may have multiple (alternative) production plans.

\footnotetext{
'This is a departure from previous descriptions of Virtuc. Previously, each member of the enterprise distributed his catalog to a select set of members; this distribution system defined the enterprise procurement channcls. This concept of static infrastructure has been deleted from the model; instead, links between arbitrary members are now established dynamically, through the exccution of transactions.
} 


\subsection{Transactions}

Since component products are often obtained from other enterprise members, a procurement mechanism is necessary. Procurement is executed in transactions. A transaction begins when a request for a catalog product (content or process) is sent from one participant to another, and terminates when the request is satisfied. There are two types of transactions in a virtual enterprise. An external transaction is a request for a product that is submitted from a client to one of the members of the virtual enterprise. The member processes the request and provides a solution. A member of the virtual enterprise who processes an external transaction acts in the role of a provider. To satisfy an external transaction, a provider may decide to purchase products from other members. Such transactions are internal. A member of the virtual enterprise who processes an internal transaction acts in a role of a subcontractor. The execution of external transactions is the ultimate purpose of the virtual enterprise. Each member of a virtual enterprise may act as a provider on some transactions and as a subcontractor on other transactions.

\subsection{Performance indicators and constitutional rules}

VirtuE allows the definition of performance indicators, which are formulas that capture various quantitative characteristics of the virtual enterprise; for example, the enterprise assets or interdependence levels. Another feature of VirtuE are constitutional rules, which are constraints that express behavior standards that are expected. Such rules enable virtual enterprises with different style or flavor; for example, an organization which is without any competition (similar products are not available from different members), or an organization that resembles a free market. Compliance with constitutional rules is monitored and disseminated, but not enforced.

Figure 1 illustrates the relationships among some of the basic concepts. The box indicates an enterprise member $m_{i}$. The incoming arrow on the left is a request (via a transaction $t$ ) for a product $c$. The outgoing arrow on the left is the eventual satisfaction of this transaction with the requested product. The circle indicates a production plan that $m_{i}$ uses for manufacturing product $c$. This particular plan requires the importation of two component products $c_{1}$ and $c_{2}$. The two subcontracts are executed in transactions $t_{1}$ and $t_{2}$.

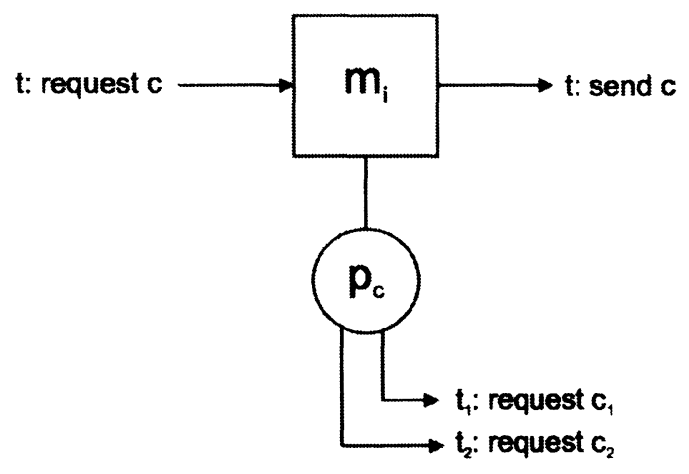

Figure 1: Basic VirtuE interactions. 


\section{EVOLVING VIRTUE}

Evolving VirtuE supplements the features summarized in the previous section with several new concepts, including time, activity logging, internal dissemination of enterprise information, and behavior mining. We begin by introducing the catalyst: a privileged member of the enterprise who has specific duties.

\subsection{The Catalyst}

The launching of a new virtual enterprise begins when a player of the VBE assumes the role of catalyst [2]. The catalyst has a business plan, knowledge of the additional expertise and resources needed to accomplish the business plan, and information on VBE players that can satisfy these needs. The catalyst is a privileged member of the virtual enterprise, with several exclusive roles, such as changing the membership of the enterprise or modifying its goals (i.e., end products). In Evolving VirtuE, the catalyst role consolidates several distinct organizational roles, such broker, planner and coordinator [1].

\subsection{Time and Logging}

Evolving VirtuE incorporates the concept of time. Time is simply a system-wide clock that is stamped on transactions and other enterprise events. The availability of a system clock allows for the introduction of various new performance indicators and constitutional rules. For example, indicators may be defined now to count the number of transactions performed over a period of time, or the average turnaround time. Rules may be established that require members to maintain activity at some minimal frequency, or limit the number of transactions in a given period.

Enterprise events, such as execution of transactions, updates of the catalog, or changes in membership, are now recorded in a $\log$. Log records provide essential information on each such event and the time of its occurrence. There are two types of log: local and global. Every enterprise member maintains his own local log, and, in addition, there is an enterprise-wide log. Local logs may be used by members to improve their operations. The global $\log$ can be used for studying enterprise-wide performance, as well as for communication among members.

\subsection{Information dissemination and behavior mining}

Altogether, Evolving VirtuE incorporates four global information resources: the product dictionary, which describes products and types; the product catalog, which lists the products available from members; the log, which chronicles the activities of the enterprise; and the constitution, which establishes the conventions of the enterprise. These resources are managed by the catalyst (who could also designate another member to act as the information manager). It is important to note that the information in these global resources is maintained and processed in a manner 
identical to any other content. ${ }^{2}$ Thus, the catalyst can supply other members with products that calculate performance indicators, or assess compliance with constitutional rules. This information is exchanged using the ordinary transaction mechanism of VirtuE.

The information derived from the enterprise information resources need not be limited to the calculation of performance measures or the validation of constitutional rules. The global log, and to some degree the other information resources, can be subjected to a wide array of data mining techniques. The overall purpose is to study the performance and behavior of the enterprise, and to associate the outcome with various evolutionary decisions. This subject is discussed further in Section 4.

Recall that the dictionary and the constitution describe, respectively, the product types of the enterprise and the restrictions on its behavior. ${ }^{3}$ Only the catalyst is allowed to modify the dictionary and the constitution, but all members can retrieve its information. The catalog is the set of products that are available from individual members - it is a union of the individual inventories. Each member can update his own portion of the catalog, and retrieve information on other inventories. The log is updated automatically after various enterprise activities, and can be examined by everyone.

\section{CREATION AND EVOLUTION}

One notable period of virtual enterprise evolution is the initial stage of its formation. In this period, the new virtual enterprise goes through a period of repetitive refinement, until it acquires stability, at least for a while.

Virtual enterprise creation begins when a VBE player decides to launch a virtual enterprise for some product (or set of products). This participant acts as the catalyst of the virtual enterprise, and performs these initial actions:

1. Initialize the four repositories: the constitution, the dictionary, the catalog, and the log. Update the constitution with the enterprise rules, and update the dictionary with the product types and descriptions envisioned for the enterprise. The catalyst has thus set the "charter" for the enterprise: its product line and its business style.

2. Invite other VBE participants to join the enterprise; they become members of the enterprise.

Members retrieve information from the dictionary and catalog, and decide the products they wish to manufacture for the enterprise. A member who decides to manufacture a product of a type that appears in the dictionary, defines a production plan for the product and updates the catalog with the new product and its specification. Occasionally, a new production plan may necessitate a product of a new type, not yet in the dictionary. In this case, the member writes the proposed dictionary update to the $\log$. Thereafter, the catalyst examines the log and updates the dictionary appropriately. The member can then complete the definition of the new product.

\footnotetext{
${ }^{2}$ This is analogous to the way database management systems use standard database structures to maintain meta-information such as schema, integrity constraints, and access permissions.

${ }^{3} \mathrm{~A}$ possible analogy from the area of database management, is to perceive the dictionary and constitution as, respectively, the "schema" and the "integrity constraints" of the enterprise.
} 
This process - in which new products are defined, new production plans are established, and the product dictionary and catalog are updated - is repeated, until stability is achieved: The enterprise is then ready for transacting business.

This process of creation demonstrates how enterprise information sources are consulted continuously for making decisions; in this case, addition of product types and product instances. More generally, Evolving VirtuE provides a framework for studying the behavior of the enterprise and taking corresponding actions.

This activity may be performed by individual enterprise members, who may follow up their conclusions with business decisions, intended to improve their own performance. For example,

- Whom should I work with? A member may extract from the global and local sources data on the recent performance of potential transaction partners, and the cost of their services, and use it to improve the turnaround time for his products.

- Should I make it or should I buy it? This classical business decision can be resolved based on information mined from the global resources, using data on prices charged and delays incurred (plus estimation of local production and processing costs).

- Which production plan should I use? Similarly, recent data on the time and cost required to obtain necessary component products (plus estimation of local production and processing costs) can be used to decide which of alternative production plans to use.

The mining activity may also be performed by the catalyst, who may follow up with more far-reaching conclusions, intended to affect the overall behavior of the enterprise. For example,

- Improving overall enterprise performance by changing membership. By analyzing turnaround times for various products, the catalyst may identify members who are overloaded with orders (causing long transaction completion times), and thereby invite new members with equivalent capabilities. Conversely, the catalyst may identify members who are no longer active and dismiss them from the enterprise.

- Improving overall market responsiveness by changing the product line. By analyzing $\log$ information on external transactions, the catalyst may identify market trends, and modify or expand the product offerings of the enterprise to respond to the new trends. Conversely, the catalyst may delete products for which there is no longer demand. In effect, the enterprise would be evolving its product dictionary.

- Monitoring enterprise behavior. The global information sources provide the data for calculating performance indicators and testing compliance with constitutional rules. The results of such monitoring could be associated with triggered actions. For example, warning may be sent to a member who is violating a component of the "charter". 


\section{BACKGROUND}

The literature on virtual enterprises is considerable, and for the sake of brevity we limit our discussion to work that is directly related to the main focus of this paper, which is creation, learning and evolution.

Creation and evolution is strongly dependent on the availability of flexible infrastructures. Camarinha-Matos and Afsarmanesh [5] discuss approaches and trends in architectures for flexible infrastructures and breeding environments.

Experience in building a technological infrastructure for supporting the creation, operation and dissolution stages within the lifecycle of a virtual enterprise is discussed in [8].

Tagg [10] observed three stages in the life of a virtual enterprise: establishment, which focuses on building relationships, a fundamentally iterative activity; business development, when more formal cycles of invitations to tender, joint proposals, cooperative market research are accomplished; and business execution, when processes and workflows are most similar to those of single organizations.

Social Actors Networks (SAN) are used in [9] for modeling collaborations in virtual enterprises. The authors propose SAN analysis to support the identification of the actors involved, their role and importance, and their supplying characteristics (e.g., types of products or delivery performance).

The issue of partner evaluation and selection in considered in [11]. The authors stress the importance of knowing the capability and compatibility of potential partners, and suggest a profile-based approach for measuring these factors.

Issues of selecting business partners, coordinating the distribution of production processes, and the prediction of production problems are studied in [7]. The authors seek to provide decision support for virtual enterprises by using a Neural On-Line Analytical Processing System (NOLAPS). Their system incorporates two components: It uses neural networks for extrapolating probable outcomes based on available patterns of events, and data mining for converting complex data into useful corporate information. The approach has been validated with a prototype system and an example case.

\section{CONCLUSION}

In this paper we introduced Evolving VirtuE, a model for virtual enterprises with features that support learning and evolution. In particular, it incorporates time, activity logging, and internal dissemination of enterprise information. These create a framework for continuous study of enterprise behavior through data mining techniques. Conclusions from such discoveries are then linked to specific evolutionary actions.

For reasons of space we did not elaborate on various details, including the types of events that are logged and the exact information stored, or particular data mining techniques. Still, much work remains to be done, and we mention here two current research directions. 
Work is underway on suitable techniques of mining data from logs of virtual enterprises, and, possibly, on a decision support system that will associate discoveries with specific actions. Also, recognizing that centralized information sources in a distributed environment can cause undesirable bottlenecks, work is underway to decentralize these resources, possibly by adopting a grid architecture.

\section{Acknowledgement}

This work was performed within Interop: Interoperability Research for networked Enterprises Applications and Software, European Network of Excellence IST-508011 (http://interop-noe.org), and has been partially supported by the SFIDA-PMI project.

\section{REFERENCES}

1. Afsarmanesh H, Camarinha-Matos L.M. A framework for management of virtual organization brecding environments. In Proc. PRO-VE 05: Collaborative Networks and their brecding environments, IFIP 6th Working Conf. on Virtual Enterprises, pp. 35-48, Kluwer 2005.

2. D'Atri A. Organizing and managing virtual enterprises: the ECB framework. In Proc. PRO-VE 03: Processes and Foundations for Virtual Organizations, IFIP 4th Working Conf. on Virtual Enterprises, pp. 171-178, Kluwer, 2004.

3. D'Atri A, Motro A. VirtuE: virtual enterprises for information markets. In Proc. ECIS 02, 10th Europcan Conf. on Information Systems; Rescarch Track: Digital Economy - Modcls for c-Business and m-Busincss, pp. 768-777, 2002.

4. D'Atri A, Motro A. VirtuE: a formal model of virtual enterprises for information markets. Journal of Intelligent Information Systems, to appear, on-line at http://www.springerlink.com, 2007.

5. Camarinha-Matos L.M., Afsarmanesh H. Elements of base VE infrastructure. J. Computers in Industry, 51(2), pp. 139-163, 2003.

6. Goranson HT. The agile virtual enterprisc: cases, metrics, tools. Quorum Books, Westport, CT, 1999.

7. Lau HCW, Chin KS, Pun KF, Ning A. Decision supporting functionality in a virtual enterprise network. Expert Systems with Applications, 19(4), pp. 261-270, 2000.

8. Nayak N, Chao T, Li J, Mihacli J, Das R, Dercbail A, Soo Hoo J. Role of technology in enabling dynamic virtual enterprises. In Proc. Int. Workshop OES-SEO 2001: Open Enterprisc Solutions: Systems, Experiences and Organizations, Luiss Edizioni, Rome, 2001.

9. Soarcs AJ, Sousa JP, Barbedo F. Modeling the Structure of Collaborative Networks: Some Contributions. In Proc. PRO-VE 03: Processes and Foundations for Virtual Organizations, IFIP 4th Working Conf. on Virtual Enterprises, pp. 23-30, Kluwer, 2004.

10. Tagg R. Workflow in different styles of virtual enterprisc. In Proc. the Workshop on Information Technology for Virtual Enterpriscs, ITVE, Vol. 13, pp. 21-28, 2001.

11. Tsakopoulos S, Bokma A, Plckhanova V. Partner cvaluation and selection in virtual enterprises using a profile theory based approach. In Proc. PRO-VE 03: Processes and Foundations for Virtual Organizations, IFIP 4th Working Conf. on Virtual Enterprises, pp. 73-84, Kluwer, 2004. 